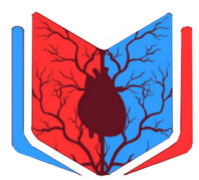

Published By : IVAA

the Indonesian Vascular Access Association

\title{
Deep Venous Thrombosis (DVT) risk assessment on routine hemodialysis patient using Padua prediction score
}

\author{
Benny Tjan ${ }^{1 *}$, I Gusti Ngurah Agung Tresna Erawan², Yenny Kandarini ${ }^{2}$
}

1 General Practitioner of Bali Husada Cipta Canthi Main Clinic, Denpasar, Bali, Indonesia

${ }^{2}$ Division of Nephrology and Hypertension, Department of Internal Medicine, Faculty of Medicine Universitas Udayana, Sanglah General Hospital, Bali, Indonesia
*Corresponding to:

Benny Tjan; General Practitioner of

Bali Husada Cipta Canthi Main Clinic, Denpasar, Bali, Indonesia;

Email:bennytjan1993@gmail.com

\section{Received:2021-05-09}

Accepted: 2021-11-25

Published: 2021-12-28

\section{ABSTRACT}

Introduction: Hemodialysis requires invasive vascular access (VA) procedure which could emerge deep venous thrombosis (DVT) complication. Apart from VA, other risk factors, either modifiable or unmodifiable, could increase DVT risk. Those factors can be assessed by Padua Prediction Score (PPS). This study aims to assess which risk factors in PPS increase the risk of developing DVT in routine hemodialysis patients at BHCC main clinic.

Methods: This research is a descriptive observational study with simple random sampling. The participants were 58 routine hemodialysis patients in BHCC. The inclusion criteria of this study were the ages above 17 years old, had history hemodialysis more than one, the patient willing to become of the sample subject. The patient that incompletely fulfills the questionnaire were already treated with anticoagulation were admitted for VTE, and had a history of discontinuing hemodialysis were excluded. The data were gathered using a questionnaire according to PPS. The data was analyzed by using SPP 25.0. The descriptive data was provided in a table and pie chart.

Results: Based on the results of the PPS, 11 patients (18.96\%) were among the high risk, and 47 patients (81.04\%) were at low risk. The most potent risk factor in increasing the risk of DVT is reduced mobility with a risk priority number (RPN) of 30 (severity $=3$, occurrence $=10$ ). Recent ( $\leq$ one month) trauma and surgery entail on second with an RPN of 24 (severity $=2$, occurrence $=12$ ). The third is occupied by heart and/or respiratory failure with a RPN of 14 (severity=1, occurrence $=14$ ). Previous VTE history with a RPN of 12 (severity $=3$, occurrence $=4$ ) placed fourth, followed by age $\geq 70(R P N=8$, severity $=1$, occurrence $=8$ ) and obesity $(\mathrm{BMI}>=30$ ) with a RPN of 4 (severity $=1$, occurrence $=4)$ at fifth and sixth respectively.

Conclusion: "Reduced mobility" is the most prominent risk factor to increase DVT risk in routine hemodialysis patients, followed by other risk factors. Reduced mobility and obesity are modifiable risk factors that should be eliminated by educating routine hemodialysis patients.

Keywords: deep venous thrombosis, vascular access, hemodialysis, Padua prediction score.

Cite This Article: Tjan, B., Erawan, I.G.N.A.T., Kandarini, Y. 2021. Deep Venous Thrombosis (DVT) risk assessment on routine hemodialysis patient using Padua prediction score. Journal of Indonesia Vascular Access 1(2): 32-34. D0I : 10.51559/jinava. v1i2.15

\section{BACKGROUND}

Routine hemodialysis gives many physiologic and quality-life benefits to patients with ESRD. Patients undergoing routine hemodialysis should use vascular access (VA). This invasive procedure that potentially harms the vascular must be carefully evaluated because of the various complications. One of the complications of vascular access is deep venous thrombosis. Apart from VA, other risk factors, either modifiable or unmodifiable, could increase DVT risk. Those factors can be assessed by Padua Prediction Score (PPS). PPS had been created to assess the risk of venous thrombosis in patients. ${ }^{1}$ There are 11 items with their score to assess. The patient with PPS $\geq 4$ is categorized in high-risk venous thrombosis. ${ }^{2}$ Other research about Padua prediction score and thrombin generation found that $73.9 \%$ of patients had Padua score $<4$, and the rest had Padua score $\geq 4$. Comparison of the thrombogram parameters between the two Padua score categories showed no significant difference; lag time $(\mathrm{P}=0.066)$, ETP $(P=0.266)$, peak height $(P=0.418)$, and time to peak $(\mathrm{P}=0.415){ }^{3}$ This study aims to assess which risk factors in PPS increase the risk of developing DVT in routine hemodialysis patients at BHCC main clinic.

\section{METHODS}

This research is a descriptive observational study with simple random sampling. The participants of this study were 58 routine hemodialysis patients in the main clinic, BHCC. The data were taken using a questionnaire adjusted to the contents of the Padua Prediction Score while the patient underwent routine hemodialysis. Then we calculated the PPS score and categorized the patient into high or low risk. We also determined which risk factors were most potent to lowest. The inclusion criteria of this study were the ages above 17 years old, had history hemodialysis 
more than one, the patient willing to become of the sample subject. The patient that incompletely fulfills the questionnaire were already treated with anticoagulation, admitted for VTE, and had a history of discontinuing hemodialysis were excluded. The data were analyzed by using SPSS 25.0. The descriptive data was provided in a table and pie chart.

\section{RESULT}

Based on the results of the PPS, 11 patients (18.96\%) were among the high risk, and 47 patients $(81.04 \%)$ were at low risk. The most potent risk factor in increasing the risk of DVT is reduced mobility with a risk priority number (RPN) of 30 (severity $=3$, occurrence $=10)$. recent $(\leq$ one month) trauma and/or surgery" entails on second with an RPN of 24 (severity=2, occurrence $=12$ ). The third is occupied by "heart and/or respiratory failure" with a RPN of 14 (severity=1, occurrence=14). Previous VTE history with a RPN of 12 (severity $=3$, occurrence $=4$ ) placed fourth, followed by age $\geq 70$ (RPN $=8$, severity $=1$, occurrence $=8)$ and obesity $(B M I \geq 30)$ with a RPN of 4 (severity $=1$, occurrence $=4$ ) at fifth and sixth respectively. Already known thrombophilic condition is the least risk factor with RPN of 3 (severity $=3$, occurrence $=1$ ). The remaining other factors do not contribute to the increased risk of DVT.

\section{DISCUSSION}

Based on PPS, we can see that $18.96 \%$ of patients with routine $\mathrm{HD}$ in BHCC have a high risk of DVT. In addition to knowing the high-risk percentage, we also look at which risk factors have the most influence on PPS scores, both in low-risk and high-risk patients. From the results, reduced mobility is the most contributor to PPS score with RPN 30. Reduced mobility has the most incidence, namely ten patients. Supported by a high severity score (3) makes reduced mobility the most influential risk factor. Patients who choose reduced mobility are those who are $\geq 70$ years old (RPN $=8$, severity $=1$, occurrence $=8)$ and obesity (BMI $\geq$ 30) $(\mathrm{RPN}=4$, severity $=1$, occurrence $=$ 4). This suggests that the risk factors for elderly patients and obesity are positively

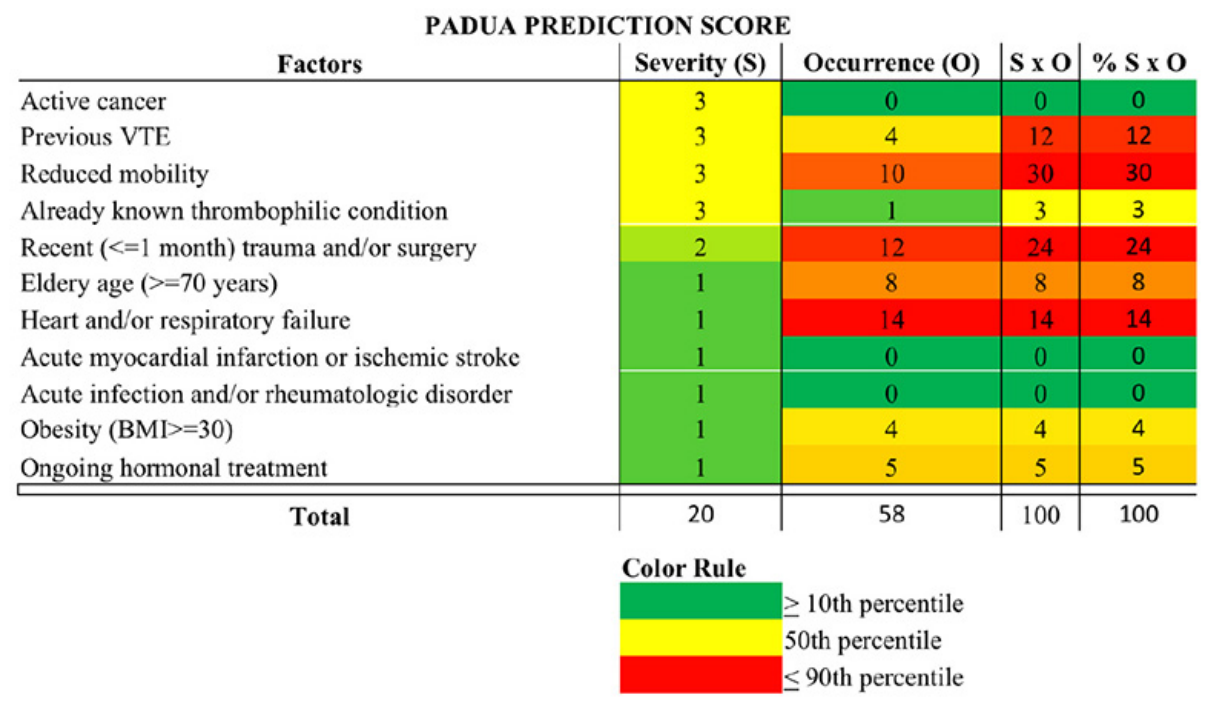

Figure 1. A Padua prediction score
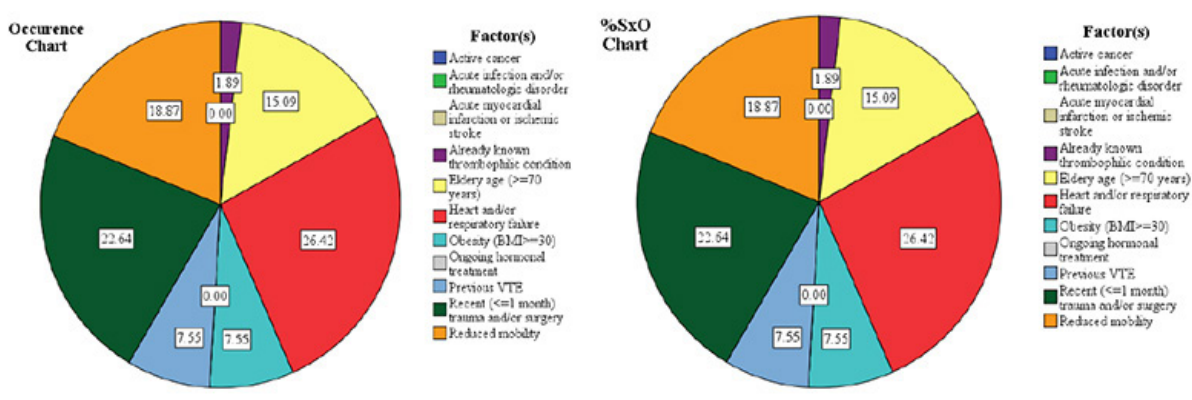

Figure 2. Pie chart related to the factors of DVT

related to the lack of mobility. Lack of mobility results in stasis of blood flow in the veins, leading to DVT. So it is important to educate obese and elderly patients to do physical activity. If it is not possible to actively move, elastic compression stockings on the knee can reduce the incidence of this risk factor. ${ }^{4-7}$

The recent (sone month) trauma and/ or surgery entails on second with a RPN of 24 (severity $=2$, occurrence $=12$ ). The trauma experienced by patients is falling, and they are $\geq 70$ years old. It is important to educate elderly patient families to pay attention to patient activities at home. In contrast, the history of frequent operations is the installation of CDL and AVF. Based on other studies, the incidence of DVT occurred in $25 \%$ of patients who underwent general surgery. This risk can be reduced by using compression devices on the legs and administering anticoagulants before and after surgery.,
The third is occupied by heart and/ or respiratory failure with a RPN of 14 (severity $=1$, occurrence $=14$ ). Fourteen patients said they had a history of heart failure and were on routine therapy. Other studies have shown that DVT can occur in $10-22 \%$ of CHF patients. This is due to Virchow's triad and chronic inflammation. ${ }^{7-11}$ The previous VTE history also has an important role with an RPN of 12 (severity = 3, occurrence = 4). DVT that has occurred can cause Post Thrombotic Syndrome (PTS). Within 1 to 2 years after suffering from DVT, PTS manifestations occur in $20-50 \%$ of patients. $^{6}$

The already known thrombophilic condition is the least risk factor with RPN of 3 (severity $=3$, occurrence $=1$ ). According to other studies, blood clotting disorders are often caused by genetic factors such as antithrombin III deficiency, protein C deficiency, protein $\mathrm{S}$ deficiency, Leiden 
mutation in factor $\mathrm{V}$, antiphospholipid syndrome, mutation of the prothrombin 20210A gene, hyperhomocysteinemia, impaired plasmin regeneration and increased factor II, VIII, IX, or XI. ${ }^{6}$

The limitation of this study was that the study did not assess another risk factor of DVT besides related with the hemodialysis and was only conducted in one center. We also did not assess the time of VA related to the DVT.

\section{DISCLOSURE}

\section{Funding}

None

\section{Ethical Approval}

The study is exempt from ethical approval in our institution.

\section{Conflict of Interest}

None.

\section{Author Contributions}

All of the authors already contributed in this study

\section{CONCLUSION}

The risk of thrombosis is not only caused by VA. Thrombosis prevention can be done by proper VA procedures and minimizing risk factors, especially modifiable risk factors. Reduced mobility is the most prominent risk factor to increase DVT risk in routine hemodialysis patients, followed by other risk factors. Reduced mobility and obesity are modifiable risk factors that should be eliminated by educating routine hemodialysis patients.

\section{REFERENCE}

1. Santoro D, Benedetto F, Mondello P, Pipitò N, Barillà D, Spinelli F, et al. Vascular access for hemodialysis: current perspectives. Int J Nephrol Renovasc Dis. 2014;7:281-94. Available from: https://pubmed.ncbi.nlm.nih. gov/25045278

2. BARBAR S, NOVENTA F, ROSSETTO V, FERRARI A, BRANDOLIN B, PERLATI $\mathrm{M}$, et al. A risk assessment model for the identification of hospitalized medical patients at risk for venous thromboembolism: the Padua Prediction Score. J Thromb Haemost. 2010;8(11):2450-7. Available from: http:// dx.doi.org/10.1111/j.1538-7836.2010.04044.x

3. Saliba W, Zahalka W, Goldstein L, Ron G, Elias M. Padua prediction score and thrombin generation in hospitalized medical patients. Thromb Res. 2014;134(4):803-6.

4. Magetsari R, Dewo P, Nugroho AS, Lanodiyu Z. Deep Vein Thrombosis in Elderly Patients following Surgery for Fracture of the Proximal Femur. Malaysian Orthop J. 2014;8(3):7-10. Available from: https://pubmed.ncbi.nlm.nih. gov $/ 26401228$

5. McLendon K, Goyal A, Bansal P, Attia M. Deep Venous Thrombosis Risk Factors. In: StatPearls [Internet]. Treasure Island (FL): StatPearls Publishing; 2021. Available from: https://www. ncbi.nlm.nih.gov/books/NBK470215/\%0A
6. Henke PK, Meissner MH, Wakefield TW. Risk Factor for Venous Thrombosis. In: Acute Deep Vein Thrombosis. Veinforum; 2018. p. 1-7.

7. Ginsberg JS, Hirsh J, Julian J, Vander LaandeVries $\mathrm{M}$, Magier $\mathrm{D}$, MacKinnon B, et al. Prevention and Treatment of Postphlebitic Syndrome. Arch Intern Med. 2001;161(17):2105. Available from: http:// dx.doi.org/10.1001/archinte.161.17.2105

8. KAHN SR, KEARON C, JULIAN JA, MACKINNON B, KOVACS MJ, WELLS P, et al. Predictors of the post-thrombotic syndrome during long-term treatment of proximal deep vein thrombosis. J Thromb Haemost. 2005;3(4):718-23. Available from: http:// dx.doi.org/10.1111/j.1538-7836.2005.01216.x

9. Prandoni P. The Long-Term Clinical Course of Acute Deep Venous Thrombosis. Ann Intern Med. 1996;125(1):1. Available from: http://dx.doi.org/10.7326/0003-4819-125-1199607010-00001

10. Brandjes DPM, Büller HR, Heijboer H, Huisman M V, de Rijk M, Jagt H, et al. Randomised trial of effect of compression stockings in patients with symptomatic proximal-vein thrombosis. Lancet. 1997;349(9054):759-62. Available from: $\quad$ http://dx.doi.org/10.1016/s01406736(96)12215-7

11. Willey VJ, Bullano MF, Hauch O, Reynolds M, Wygant G, Hoffman L, et al. Management patterns and outcomes of patients with venous thromboembolism in the usual community practice setting. Clin Ther. 2004;26(7):1149-59. Available from: http://dx.doi.org/10.1016/ s0149-2918(04)90187-7

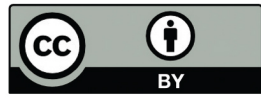

This work is licensed under a Creative Commons Attribution 